See discussions, stats, and author profiles for this publication at: https://www.researchgate.net/publication/26558977

\title{
Monetary Aggregation and Money in Production Function
}

Article in Journal of Applied Sciences · February 2002

DOI: 10.3923/jas.2002.270.272 · Source: DOAJ

CITATIONS

0

1 author:

(द)

Syed F Mahmud

Bilkent University

22 PUBLICATIONS 684 CITATIONS

SEE PROFILE

Some of the authors of this publication are also working on these related projects:

Project Herding of Locals in presence of Foreigner View project

Project Sentimental Herding and Terrorism: Evidence from Pakistan View project 


\title{
Monetary Aggregation and Money in Production Function
}

\author{
Syed F. Mahmud \\ Bilkent University Ankara, 056330 Turkey
}

\begin{abstract}
Role of real money balances as a factor input in the production function of the manufacturing sector of Pakistan has been examined. Instead of using simple sums of financial assets to represent money, we have employed a different measurement of liquidity of the firm, which includes all the assets and assigns different weights to the assets according to their ability to affect expenditures. The results suggest that real money balances do play a significant role in the production. The cross price elasticities between labour and money imply possible adverse effects of tight monetary policy on the demand for labour.
\end{abstract}

Keywords: Monetary Policy, Money Balance, Utility Approach

\section{Introduction}

In recent decades a number of studies have incorporated money as a factor of production. Nadiri (1969) pioneered this approach and using cost minimizing approach estimated firm's demand for money function for U.S. manufacturing industries. Sinai and Stokes (1972) employed Cobb-Douglas production function, with real money balances, labour and capital as factor inputs, to estimate the output elasticities for the private domestic sector of US. Dennis and Smith (1978), on the other hand, used Nadiri's cost minimizing approach, but further specified the cost function to be translog. However, in most of these studies 'money' was represented by the simple sum of cash and demand deposits. This way of representing money, as is now well-known in the literature on aggregation of money suffers from at least two shortcomings:

First it implies that other monetary assets other than cash and demand deposits do not perform any monetary function; and second, when more broader definition of money is employed (Khan et al., 1983), all the components of the aggregate get exactly the same weight ${ }^{1}$. As far as we know, no study has so far incorporated properly aggregated 'money' in the modern sense that also includes other financial assets, in their production function. One of the main purpose of this paper is remedy this deficiency.

The next question is how to obtain a money aggregate that is suitable for being used as a factor of production. One feels that one can do better than using the usual aggregate obtained through the consumer utility approach (Barnett 1980 and 1987), since the issue here is not of utility of the consumer but of the efficiency in production. In other words, here the significance of money is not to create utility, but to generate expenditure. And different forms of monetary assets do not posses this ability in proportion to their nominal values. Clements and Nguyen (1980) have provided a direct means of measuring this effectiveness in various monetary assets and have used this measure of effectiveness as weights in obtaining the aggregate. The aggregate thus obtained is obviously better suited for our purpose for the reasons mentioned above. This is what we use in this study. The next question is whether to incorporate this aggregate in a direct production function approach or the cost-minimizing approach. It has been argued that use of a cost function is more suitable when aggregated data is employed (Christensen and Greene, 1976). The first advantage of cost minimizing approach is that the right hand side variables are prices and output which can be treated as exogenous to a cost minimizing firm. Secondly, one need not to assume constant returns to scale in order to make cost shares adding up to unity. Following Denis and Smith (1978) we estimate translog cost function, which is more general than Cobb-Douglas or CES, for the Pakistani manufacturing industries.

The rest of the paper is organized as follows. In section 2, along with as brief discussion of Clements and Nguyen approach of monetary aggregation, the translog model is presented. In section 3 we discuss the data used and results of the model. Section 4 presents a summary and concluding remarks.

Model: In the first part of this section, we first discuss the monetary aggregation approach proposed by (Clements et al., 1980) Later we present the translog model used in this paper.

(Clements et al., 1980) begin with the equilibrium condition in the money market:

$L(y, r)=M / P$

Where $y$ is the real income, $r$ is the nominal rate of interest, $M$ and $P$ are the nominal quantity of money and price level respectively. Total differentiation of (1) in logarithmic form gives,

$$
\begin{aligned}
& d[\ln (P)]=d[\ln (M)]-a d[\ln (y)]-\beta d[\ln (r)], \\
& a>0 ; \beta<0 ;
\end{aligned}
$$

Instead of defining $M$ as a simple of monetary assets, (Clements et al., 1980) defined it as a linear function of the financial assets, under the assumption that these assets are not perfect substitutes:

$\mathrm{d}[\ln (\mathrm{M})]=\lambda_{1} \mathrm{~d}[\ln (\mathrm{C})]+\lambda_{2} \mathrm{~d}[\ln (\mathrm{S})]+\lambda_{3} \mathrm{~d}[\ln (\mathrm{F})]$ (3) where $C$ Is the currency and demand deposits, $S$ is savings deposits and $F$ are the fixed or long-term deposits. Equation (3) is interpreted as a liquidity production function and it is substituted back into equation (2), 
$d[\ln (P)]=\lambda_{1} d[\ln (C)]+\lambda_{2} d[\ln (S)]+\lambda_{3} d[\ln (F)]-$ a $d[\ln (y)]-\beta d[\ln (r)]$,

For an empirical estimation of (4), continuos changes are replaced by discrete changes and a lagged dependent variable is added on the right hand side to allow for the partial adjustments of prices.

$\Delta[\ln (P)]_{t}=\lambda_{1} \Delta[\ln (C)]_{t}+\lambda_{2} \Delta[\ln (S)]_{t}+\lambda_{3} \Delta$ $[\ln (F)]_{t^{-}} a \Delta[\ln (\gamma)]_{t^{-}} \beta \Delta[\ln (r)]_{t}+\delta[\Delta \ln (P)]_{t-1}+\varepsilon_{t}$

The $\lambda$ 's in (5) are the short-run elasticities. The longrun elasticities are the multiples of $(1 /(1-\delta))$. The estimated coefficients in (5) can then be used to derive the monetary aggregate in (3). Next we shall discuss the translog model.

It has been assumed that the aggregate production function can be represented by a translog production process with three inputs, namely capital, labour and real money balances. Invoking duality relations in production and cost, this can be equivalently represented by a translog cost function:

$\ln \mathrm{C}=\ln \alpha_{o}+\sum \alpha_{i} \ln P_{i}+\alpha_{q} \ln Q+\frac{1}{2} \sum \sum \alpha_{i j} \ln P_{i} n P_{j}+\sum \alpha_{i q} \ln Q \ln P_{+} \frac{1}{2} \alpha_{q q}(\ln Q)$

$i, j=m$ (real money balances), $\mathrm{N}$ (labour), $\mathrm{K}$ (capital)

Partially differentiating equation (6), invoking Shepard's lemma and imposing homogeneity, adding up and symmetry restrictions yields the following input demand equations:

$S_{i}=\alpha_{i}+\sum \alpha_{i j} \ln P_{j}+\alpha_{i q} \ln Q \quad \mathrm{i}, \mathrm{j}=\mathrm{m}, \mathrm{N}, \mathrm{K}$

Corresponding to equation (7), the Allen-Uzawa partial substitution elasticities are given by:

$$
\begin{array}{cc}
\sigma_{i j}=\frac{\alpha_{i j}+S_{i} S_{j}}{S_{i} S_{j}} & \mathrm{i}, \mathrm{j}=\mathrm{m}, \mathrm{N}, \mathrm{K} \\
\sigma_{i i}=\frac{\alpha_{i i}+S_{i}^{2}-S_{i}}{S_{i}^{2}} & \mathrm{i}, \mathrm{j}=\mathrm{m}, \mathrm{N}, \mathrm{K}
\end{array}
$$

and the price elasticities are given by:

$$
\begin{array}{ll}
\varepsilon_{i j} & =S_{j} \sigma_{i j} \\
\varepsilon_{i i} & =S_{i} \sigma_{i i}
\end{array} \quad \mathrm{i}, \mathrm{j}=\mathrm{m}, \mathrm{N}, \mathrm{K}
$$

We estimate the cost function in (6) along with the share equations in (7). Real money balances used are based on the monetary aggregation approach discussed above.

\section{Results and Discussion}

We estimate the parameters of the cost function in (1) for three factors namely, capital, labour and real money balances using annual data on aggregate manufacturing sector of Pakistan for the period 19821995.

The data on output is the value added deflated by its price index. Information on the holdings of different financial assets was taken from the publications of State Bank of Pakistan. These assets include cash and demand deposits, savings deposits and time deposits. Money balances or the liquidity of the firm was derived by using the earlier estimates of parameters of the equation (5) (Hasan et al. (1988). The parameter estimates of the macroeconomy were inserted in equation (3):

$d[\ln (M)]=.0486 d[\ln (C)]+.0297 d[\ln (S)]+.006$ $d[\ln (F)]$, and the aggregate $M$ was derived for the sample data. These balances were then divided by the output price index to obtain real money balances. Capital stock series for the manufacturing sector has been taken from the macroeconometirc model of A.E.R.C. Interest rates are the deposit rates on more than three months but less than six months. The user cost of capital is obtained by adding constant depreciation rate to the interest rates and multiplying the series by the price index of machinery. The total wages and salaries of the manufacturing sector were divided by the total employment in the manufacturing to obtain the wage rate. And finally the price of real money balances was computed by multiplying shortterm interest rates by the price of output.

The parameters of the translog cost function have been estimated by first specifying additive disturbances for the cost function (6) and the share equations (7). We have assumed that these disturbances have a joint normal distribution and have allowed for contemporaneous correlation across equations. Furthermore, the share equations in (7) must add to unity and therefore the errors in the share equations should add up to zero. This implies that one of the share equations has to be dropped. We have dropped the capital share equation.

\begin{tabular}{clll} 
Table 1: Parameter Estimates & \\
\hline$\alpha_{0}$ & -35.431 & $\alpha_{K K}$ & 0.0545 \\
& $(-1.544)$ & & $(0.866)$ \\
$\alpha_{Q}$ & 4.839 & $\alpha_{N m}$ & -0.0204 \\
& $(1.321)$ & & $(-2.287)$ \\
$\alpha_{Q Q}$ & -0.108 & $\alpha_{N K}$ & -0.0737 \\
& $(-0.341)$ & & $(-1.267)$ \\
$\alpha_{N}$ & 2.863 & $\alpha_{m K}$ & 0.0192 \\
& $(3.499)$ & & $(1.976)$ \\
$\alpha_{m}$ & 0.284 & $\alpha_{N Q}$ & -0.297 \\
& $(2.324)$ & & $(-8.314)$ \\
$\alpha_{K}$ & -2.147 & $\alpha_{m Q}$ & -0.0068 \\
& $(-2.449)$ & & $(-1.303)$ \\
$\alpha_{N N}$ & 0.094 & $\alpha_{K Q}$ & 0.3042 \\
& $(1.724)$ & & $(7.942)$ \\
$\alpha_{m m}$ & 0.0011 & D.W.(Cost) & 1.653 \\
& $(0.170)$ & D.W.(Labour) & 1.801 \\
& & D.W.(Money) & 1.745 \\
\hline
\end{tabular}

Note: t-ratios are given in the parentheses. The parameters of capital share equation were estimated using ANALYZ command in TSP.

Following Zellner (1962), the system can be estimated by using seemingly unrelated regression technique, and the estimates so obtained are invariant to the choice of the share equation to be dropped. It has been shown that Zellner's iterative method yields the maximum likelihood estimates (Dhrymes, 1970). We report the results of parameter estimates in Table 1 . In most of the cases the estimated parameters are significantly different from zero at the $95 \%$ level of confidence. Durbin-Watson statistics are also reported in the table, they do not seem to indicate any presence of serial correlation. The estimated own, cross and substitution price elasticities are mostly significant and have been 
reported in Table 2.

Table 2: Price and Substitution Elasticities

$\begin{array}{lccc}\eta_{\mathrm{NN}} & -0.3182 & \eta_{\mathrm{Nm}} & -0.03254 \\ & (-2.861) & & (-1.795) \\ \eta_{\mathrm{mm}} & -0.8706 & \eta_{\mathrm{mN}} & -1.7975 \\ & (-1.229) & & (-1.767) \\ \eta_{\mathrm{KK}} & -0.3899 & \eta_{\mathrm{NK}} & 0.5842 \\ & (-3.093) & & (15.781) \\ \sigma_{\mathrm{Nm}} & -3.6701 & \eta_{\mathrm{KN}} & 0.5707 \\ & (-1.763) & & (15.687) \\ \sigma_{\mathrm{NK}} & 0.6996 & \eta_{\mathrm{mK}} & 2.6682 \\ & (2.953) & & (2.402) \\ \sigma_{\mathrm{mK}} & 5.3219 & \eta_{\mathrm{Km}} & 0.04719 \\ & (2.408) & & (2.427)\end{array}$

Note: $t$-ratios are given in the parentheses. $\eta_{i i}$ and $\eta_{i j}$ are the own and cross price elasticities respectively. $\sigma_{i j}$ are cross substitution elasticities

The $t$-values for all the elasticities have been estimated using the Analyze option in the TSP program. As expected the own price elasticities of all the factor inputs are negative.

The signs of cross price elasticities show that labour is substitute to capital and complement to real money balances. Money and capital are substitutes to each other. Size of the cross substitution elasticities suggests limited substituion possibilities between labour and capital while money and capital are highly substitutable.

Cross price elasticity between labour and money indicate that significant increases in the interest rates may lead to decrease in the employment level in the manufacturing sector. This is an interesting result as it shows possible presence of supply-side effects of changes in interest rates on labour demand.

Comparison of these results with a model in which a narrow defination of money is employed (only cash and demand deposits) indicates that first all the cross price elasticites have the same signs. Second, the cross price elasticites of labour and capital with respect to money are significantly smaller in magnitude compared to the ones reported in Table 2 . One possible explantion of this result stems from the fact that exclusion of other finanacial assets from estimation may have lead to the measurement error problem in the earliar model. And therfore the cross price elasticities were underestimated. The other the oretical justification of this result is the fact that with more liquidity of the firm, firms have greater flexibility in their input demand responses.

\section{Conclusions}

In this paper we first introduced a properly aggregated 'money', that also includes other financial assets of the firm. We employed the methodology of Clements and Nguyen (1980), based on liquidity production function, to derive the monetary aggregate. The aggregate was then incorporated into the production function, with two other inputs labour and capital. The parameters of a translog cost function, together with the cost share equations, were estimated and both price and substitution elasticities were computed.

The results of the cross price elasticities indicate that labour is substitute to capital while it is a complement to money. And capital and money are substitutes. The degree of substitutability of money with capital was very high. The own price elasticities of labour and capital were fairly low. In general the overall significance of these elasticities do suggest that money does play a significant role in the production function as a factor of production.

Finally, although the primary focus of this study was to introduce a new monetary aggregate into the production function and to examine its role in the production, the results do suggest potential supplyside effect of a change in the interest rate on the demand for labour. For example an increase in the interest rate by $25 \%$, under a contractionnary monetary policy regime, would decrease employment almost by a percent. This result is, however, based on the cost minimizing cross price elasticity where output is exogenously determined.

\section{Acknowledgement}

The author is extremely grateful to Professor syed Ahmed (McMaster University, Canada) for his valuable comments and suggestions on an earlier draft of the paper.

\section{References}

Barnett, W. 1980. "Economic Monetary aggregates: An application of Index Number and aggregation Theory", ]. Econometrics 14, 11-48.

Barnett, W., 1987. "The Microeconomic Theory of Monetary Aggregation". In W.Barnett and K. Singleton (eds.), New approaches to Monetary Economics. Cambridge: Cambridge University Press.

Christensen, L.R. and W.H. Greene. 1976. "Economics of Scale in U.S. Electric Power generation", J. Political Economy, 84: 655-676.

Clements, K., and P. Nguyen, 1980. Economic Monetary' aggregates-Comment", 3 . of Econometrics, 14: 49-53.

Dennis, E. and ' K. Smith, 1978. "A Neo-Classical Analysis of the Demand for Real, Cash Balances by Firms," J. Political Economy, 86: 793-813.

Dhrymes, P. J., 1973. "Small" Sample and Asymptotic Relations Between Maximum Likelihood and Three Stage Least Squares

Hasan, M.A.' S.G. Kadir and S.F. Mahmud, 1988. Súbstitutability of Pakistan's Monetary' Assets under alternative Monetary Aggregates", Pakistan Development Review 3: 317-326.

Hasan, M. A. and S. F. Mahmud, 1992. "Money in the Canadian Manufacturing Industries: A Translog Cost Function Approach," Economic Notes, 21, 1: 265-280.

Khan, A. and M.Ahmed, 1985. "Real Money Balances in the Production Function of a Developing Country," Review of Economics and Statistics,

Mahmud, S.F., 1997. "Money in Production Function: Some Further Results", Pakistan Economic and Social Review, 35: 1-9.

Nadiri, M. I., 1969. "The Determinants of Real Cash Bálances in the U. S. Total manufacturing Sector", Quarterly J. Economics 83: 173196.

Simos, E., 1981. "Learning-by-Doing or Doing-byLearning? Evidence on Factor Learning and Biased Factor Efficiency Growth in the U.S." Review of Business and Economic Research, 16:
14-25.

Sinai A. and $H$. Stokes, 1972. "Real Money Balances: An Omitted Variable from the Production Function", Review of Economics and Statistics 54. 290-296.

Zellner, A., 1962. "An Efficient Method of Estimating Seemingly Unrelated Regressions and Tests for Aggregation Bias"', J. American Statistical Association 58: 348-368. 